Proceedings

\title{
Comparative Morphology and Histochemistry of the Colleterial Glands in Different-Aged Females of Coptotermes gestroi (Blattaria, Isoptera, Rhinotermitidae) ${ }^{\dagger}$
}

\author{
Iago Bueno da Silva * and Ana Maria Costa-Leonardo
}

Citation: Silva, I.B.; Costa-Leonardo, A.M. Comparative Morphology and Histochemistry of the Colleterial Glands in Different-Aged Females of Coptotermes gestroi (Blattaria, Isoptera, Rhinotermitidae), in Proceedings of the 1st International Electronic Conference on Entomology, 1-15 July 2021, MDPI: Basel, Switzerland, doi:10.3390/IECE-10542

Published: 1 July 2021

Publisher's Note: MDPI stays neutral with regard to jurisdictional claims in published maps and institutional affiliations.

Copyright: (c) 2021 by the authors. Submitted for possible open access publication under the terms and conditions of the Creative Commons Attribution (CC BY) license (http://creativecommons.org/licenses /by/4.0/).
Laboratório de Cupins, São Paulo State University, Av. 24A, 1515, Bela Vista, Rio Claro - SP, Brazil. Zip code: 13.506-900.

* Correspondence: iago.bueno@unesp.br

+ Presented at the 1st International Electronic Conference on Entomology (IECE 2021), 1-15 July 2021; Available online: https://iece.sciforum.net/.

\begin{abstract}
Colleterial glands are female accessory glands occurring in several insect lineages and may display different functions. Within Dictyoptera, they synthesize compounds present in the ootheca of cockroaches and mantises. However, their morphology and secretory activity in Isoptera have been poorly investigated hitherto. Here, we conducted a morphological and histochemical analysis on these structures in different-aged females of Coptotermes gestroi. Thus, colleterial glands were isolated from 2-d-old (non-egg-laying) and 80-d-old (egg-laying) queens, and photographed for posterior description. Isolated abdomens from alate females (non-egg-laying) and 4-yr-old queens (egg-laying) were processed for routine histology, and cross-sections of the colleterial glands were measured to compare epithelium height. Xilydine-Ponceau and PAS histochemical tests were applied for identification of total proteins and polysaccharides, respectively. Colleterial glands are composed of anterior and posterior glands, which are distally ramified but discharge in a common basal trunk. The anterior gland was always longer than the posterior one, although the latter structure was thicker than the former. Histological sections showed colleterial glands poorly developed in alate females, while they were well-developed in 4-yr-old queens. The epithelium height of both glands increased significantly in egg-laying-queens $(\mathrm{P}<0.0001, \mathrm{t}$ test $)$. Histochemical analysis showed that glycoproteinaceous secretion occurred only in the lumen of the posterior gland in 4yr-old queens, while it was absent in the lumen of their anterior gland, as well as in the lumen of both glands in alate females. Results suggest a chemical modification in the secretion of the colleterial glands during the queen life, especially associated with the oviposition process.
\end{abstract}

Keywords: Termite; exocrine glands; invasive species; glycoproteins; reproductive system; histology

\section{Introduction}

Colleterial glands, also referred to as female accessory glands, are organs associated with the reproductive apparatus of female insects. Although these structures are not omnipresent among insect taxa [1], they are always of epidermal origin, corresponding to an invagination of the oviduct and/or imaginal discs, and are usually paired organs opening next to the spermathecal duct [2]. The function of the colleterial glands vary among insects, but they are generally related to the synthesis and secretion of compounds which cover insect eggs or fixate them on the substrate [2]. Nevertheless, other exceptional functions have been observed for some groups such as aculeate Hymenoptera, in which these glands synthesize nutritional and/or poisonous contents [3].

Dictyopera is a monophyletic clade that includes cockroaches, mantids, and termites $[4,5]$. Within Dictyoptera, the colleterial glands are well-understood among cockroaches 
and mantids, whose glands are laterally-disposed and secrete compounds which are mixed and ultimately result in a hardened casing, the ootheca [6,7]. The ootheca, in turn, covers the clustered eggs during the oviposition, preventing their desiccation and/or predation [8]. In termites, the colleterial glands are not-well-understood and even basic information is lacking for some families.

The colleterial glands of termites open via a common basal trunk into the genital chamber. Such a trunk is involved by circular and longitudinal muscle layers and bifurcates into the anterior and posterior glands, which in turn divide into convoluted tubules $[9,10]$. The anterior colleterial gland seems to be longer and well-developed when compared to the posterior one, especially in functional queens [7,11]. Nevertheless, few morphological comparisons were already conducted among termite families, especially concerning the gland opening and structure of the anterior and posterior glands [7]. Chemical aspects of the colleterial glands within Isoptera, as well their likely function, are still unclear, given that most termite species lay eggs individually, without any covering [7].

Coptotermes gestroi (Rhinotermitidae) is a subterranean termite species of particular economic importance, whose current distribution concentrates in the equatorial zone $[12,13]$. Colonies of $C$. gestroi are generally headed by a single royal pair that establishes nests after the swarming flight, and reproductive dynamics is based on the high capacity of egg-laying in the referred species [14]. Similar to most termite species, C. gestroi queens lay individual eggs, but a comprehensive analysis of the colleterial glands related to the age and reproductive dynamics of this species has not been conducted hitherto. Moreover, basic information concerning these glands in Rhinotermitidae is lacking. Aiming to contribute to the knowledge of the reproduction in this termite species, we conducted morphological and histochemical analyses of the colleterial glands in different-aged females of C. gestroi.

\section{Material and Methods}

\subsection{Termites}

Alate females and males of Coptotermes gestroi (Wassman, 1896) were collected during swarming flights in the city of Rio Claro, SP, Brazil. The individuals were separated by sex and randomly paired in $9 \mathrm{~cm}$ Petri dishes containing moistened and decayed Pinus sp. sawdust. Non-egg-laying queens were obtained from the swarming flights (alate females) and from 2-d-old colonies after pairing. Egg-laying queens were obtained from 80-d- and 4-yr-old colonies maintained under laboratory conditions.

\subsection{General morphology of the colleterial glands}

For these analyses, queens from 2-d- and 80-d-old colonies were selected, corresponding to non- and egg-laying queens, respectively. Five females of each group were dissected in physiological saline solution under Zeiss Discovery V8 stereomicroscope with the aim of forceps. The colleterial glands were isolated, stained with aqueous Eosin, and photographed for posterior description.

\subsection{Histology, Histochemistry, and morphometry of the colleterial glands}

Abdomens of at least three alate females and queens from 4-yr-old colonies (egglaying queens) were fixed in FAA (absolute alcohol, glacial acetic acid, 40\% formaldehyde, in the ratio 3:1:1) or alcoholic Bouin for $24 \mathrm{~h}$. The samples were then dehydrated in an ethanol series (70-95\%), transferred to a Leica ${ }^{\circledR}$ historesin solution, and kept in a refrigerator for 7 days. After, the material was placed in molds, which were filled with Leica® historesin plus catalyzer for polymerization. The abdomens were sectioned with a $3 \mu \mathrm{m}$ thickness using a Leica RM 2245 microtome. For morphological description, histological sections were stained with hematoxylin-eosin (HE). For detection of polysaccharides/glycoproteins and total proteins, sections were stained with PAS and xylidine-Ponceau, respectively. Aiming to evaluate morphometrical changes in the colleterial glands, we 
randomly selected nine cross-sections of each gland in two different females from each group (non- and egg-laying females). The epithelium height was measured using the "straight tool" of the software (https://imagej.nih.gov/ij), and posteriorly compared using the software R [15].

\section{Results}

Colleterial glands of $C$. gestroi females are composed of anterior and posterior glands, which are distally ramified but join in a common short basal canal located at the $9^{\text {th }}$ esternite. Thus, the glands open into the genital chamber via a single trunk, next to the spermathecal duct. Both glands are bifurcated, constituted of a tubule set and were easily distinguished, since the anterior glands were always longer than the posterior ones, although the epithelium of the latter structures was thicker.

Histological sections of the abdomen evidenced that the colleterial glands are less developed and restricted to the $9^{\text {th }}$ esternite in alate females, while these structures are well-developed in queens from 4-yr-old colonies (egg-laying queens), extending deeply into the abdomen (Figure 1a-b). Moreover, the morphology of anterior and posterior glands were similar in the histological sections from alate female abdomens. On the other hand, egg-laying queens showed an anterior gland with large lumen, whereas the posterior gland was composed of a narrow lumen, but well-developed epithelium, corroborating morphological and morphometrical data provided here. The morphometrical evaluation showed that epithelium height of both glands increased in egg-laying-queens from 4-yr-old colonies $(\mathrm{P}<0.0001$, $\mathrm{t}$ test $)$.

The secretion present in the lumen of the posterior gland distal tubules was weakly stained with xylidine-Ponceau in queens from 4-yr-old colonies (Figure 1d). However, the same secretion was strongly stained with PAS (Figure 1f). Although differences in staining intensity were observed, histochemical tests suggest the occurrence of glycoproteins in the lumen of the posterior gland. The lumen of the distal tubules of the anterior gland, in turn, did not react to any histochemical test in both females (Figure 1c-e), similar to that of posterior gland in alate females (Figure 1c).

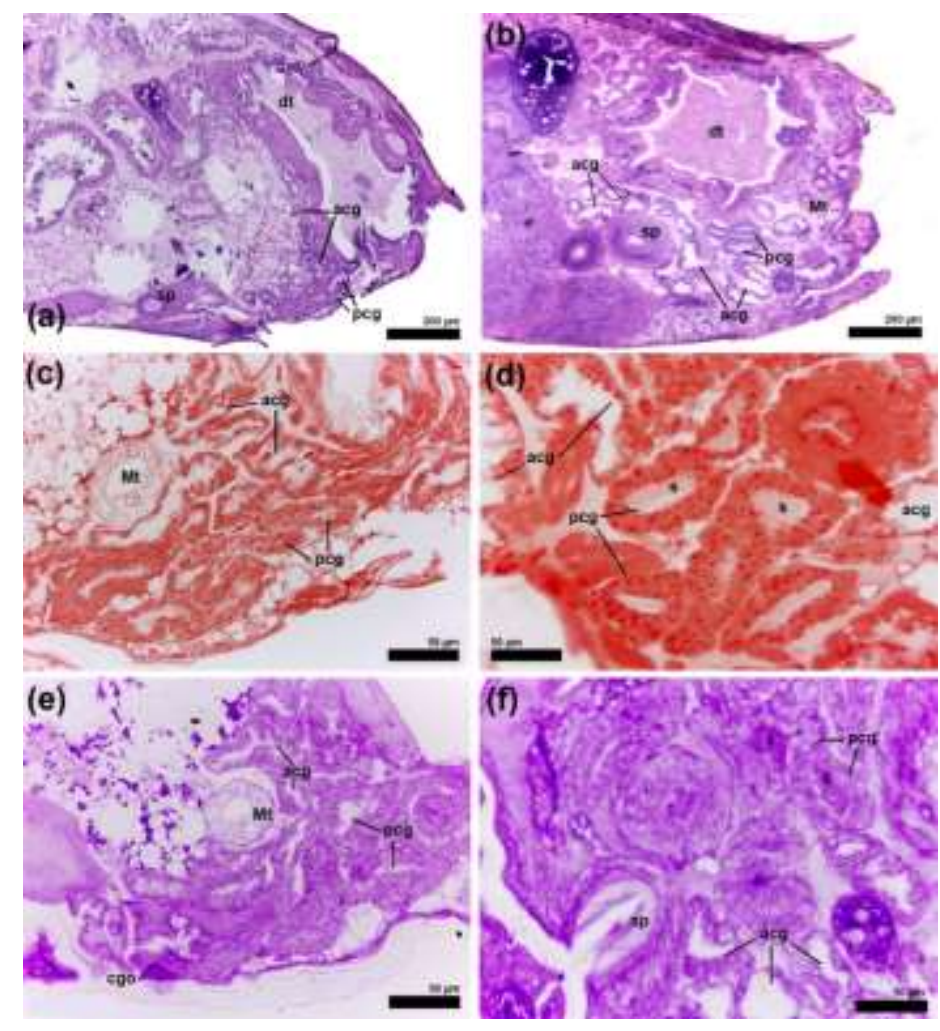


Figure 1. Histology and histochemistry of the colleterial glands in different-aged females of C. gestroi. (a) General view of the colleterial glands in alate female. (b) General view of the colleterial glands in 4-yr-old queen. Stain: Hematoxylin-eosin. (c) Detail of the colleterial glands in alate female, showing the lumen of the anterior gland tubule devoid of protein. (d) Detail of the colleterial glands in 4-yr-old queen with secretion weakly stained in the lumen of the posterior gland tubule. Stain: xylidine-Ponceau. (e) Anterior and posterior colleterial glands in alate female. (f) Anterior and posterior colleterial glands in 4-yr-old queen with secretion strongly stained in the lumen of the posterior gland. Stain: PAS. acg = anterior colleterial gland, $\mathrm{cgo}=$ colleterial glands opening, $\mathrm{dt}=$ digestive tube, $\mathrm{Mt}=$ Malpighian tubule, $\mathrm{pcg}=$ posterior colleterial gland, $\mathrm{s}=$ secretion, $\mathrm{sp}=$ spermatheca.

\section{Discussion}

The general morphology of the colleterial glands from C. gestroi females resembles those of Kalotermes flavicollis and Cubitermes fungifaber, in which both glands are distally ramified but join basally in a common trunk [10-11]. Nevertheless, our observations differ from observations performed on Mastotermes darwiniensis, Zootermopsis nevadensis, and Pseudacanthotermes spiniger, in which the anterior gland is paired and well-developed, while the posterior one is a reduced structure [7]. Despite the differences between the anterior and posterior glands, these structures showed some specific morphological features in C. gestroi. For example, regardless the reproductive status of the females, the anterior gland was thin and extremely extended, whereas the posterior gland was always thicker than the anterior one, exhibiting a well-developed epithelium, which seems to be a novelty for the colleterial glands of termites.

Variation in the glandular opening has hitherto been reported for some species. The colleterial glands of $M$. darwiniensis, Z. nevadensis, and P. spiniger show a basal trunk each, which opens individually into the genital chamber [7]. According to our observations, the colleterial glands of $C$. gestroi also show a trunk prior to the bifurcation of the gland tubules. However, both glands open in a common basal canal into the genital chamber, at the $9^{\text {th }}$ esternite, similar to that described for Tenuirostritermes tenuirostris, C. fungifaber, and K. flavicollis [9-11].

Our current histological and histochemical results in non- and egg-laying-queens evidenced the development and physiological changes of these glands as the queens started the oviposition. The anterior and posterior glands did not show histological differences in alate females, similar to the observations described by Soltani-Mazouni and Bordereau [11] for pseudergates of $K$. flavicollis. However, in egg-laying queens from 4-yr-old colonies, the glands are easily distinguishable, since the anterior gland shows a large lumen while the posterior one is narrowed, filled with reticulate secretion, and surrounded by a well-developed epithelium. Such morphological features are in accordance with those described for mature neotenic reproductives of K. flavicollis [11].

The occurrence of luminar secretion in the posterior colleterial gland of C. gestroi differs from previous reports on M. darwiniensis, Z. nevadensis, and P. spiniger [7]. According to these authors, the posterior glands were less developed in the referred species and devoid of secretion in the glandular lumen. Nevertheless, our histochemical tests evidenced the occurrence of glycoproteinaceous secretion only in the lumen of the posterior gland in egg-laying queens, whereas no positive reaction to the histochemical tests was observed in the lumen of both glands in non-egg-laying females. Thus, the current results suggest that the glands may secrete different compounds, which seems to be associated with the oviposition process. According to Courrent et al. [7], the anterior and posterior glands of termites are likely to be homologous to the left and right colleterial glands of cockroaches, respectively. In these insects, the morphology and size of the glands vary among species based on the egg-laying behavior performed by females and ootheca size [6].

Secretion from different chemical nature may be synthesized by the colleterial glands of insects. In Bombyx mori, for example, the colleterial glands secrete a viscous compound containing mainly by water, but also proteins and polysaccharides [16]. In other groups such as grasshoppers and crickets [17-18], proteins and lipids are secreted by these structures. The protective function of the colleterial glands also includes the synthesis of the 
different compounds which ultimately results in the hardened ootheca of some cockroaches [6,19] and on the secretion of antibacterial proteins [20-21]. Beyond their function in producing compounds responsible for egg protection and fixation, the colleterial glands may serve as transport agent of sugar, ions, monoacids, and nucleotides [22], and secrete compounds to lubricate the oviducts during the process of oviposition [23]. Further investigations are necessary to understand the secretion produced by the colleterial glands in C. gestroi females and its role in the reproductive biology of these insects.

\section{Conclusions}

Colleterial glands in C. gestroi females are composed of a narrow and extended anterior gland and a short and thicker posterior one. Both glands are distally ramified but join in a common basal trunk, which opens into the genital chamber. Such morphological features resemble those reported for T. tenuirostris, C. fungifaber, and $K$. flavicollis, but differs from those described for M. darwiniensis, Z. nevadensis, and P. spiniger. It suggests that the morphology of the colleterial glands vary among and within families. Our morphometrical, histological, and histochemical data indicated developmental and physiological changes on the colleterial glands of non-egg-laying queens when comparing to those in oviposition, especially concerning the glycoproteinaceous secretion synthesized by the posterior gland of egg-laying-queens. Further analyses are encouraged to understand the secretory activity of the colleterial glands in C. gestroi females and identify other compounds associated with the colleterial glands and the oviposition dynamics in this species.

Funding: This research was funded by Coordenação de Aperfeiçoamento de Pessoal de Nível Superior - CAPES (Financial code 001).

Institutional Review Board Statement: Not applicable.

Informed Consent Statement: Not applicable.

Data Availability Statement: Data sharing not applicable.

Conflicts of Interest: The authors declare no conflict of interest.

\section{References}

1. Matsuda, R. The Morphology and Evolution of the Insect Abdomen. Pergamon Press: Oxford, 1976; 533p.

2. Gillott, C. Insect Accessory Reproductive Glands: Key Players in Production and Protection of Eggs. In Chemoecology of Insect Eggs and Egg Deposition. Hilker, M., Meiners, T. Eds. Blackwell Publishing: Berlin, 2002; pp. 37.

3. Gnatzy, W.; Volknandt, W.; Dzwoneck, A. Egg-laying behavior and morphological and chemical characterization of egg surface and egg attachment glue of the digger wasp Ampulex compressa (Hymenoptera, Ampulicidae). Arthropod struct. dev., 2018, 47, 74-81.

4. Lo, N.; Tokuda, G.; Watanabe, H.; Rose, H.; Staylor, M.; Maekawa, K.; Bandi, C.; Noda, H. Evidence for multiple gene sequences indicates that termites evolved from wood-feeding cockroaches. Curr. Biol. 2000, 37, 55-66. doi: https://doi.org/10.1016/S09609822(00)00561-3

5. Legendre, F.; Nel, A.; Svenson, G.J.; Robillard, T.; Pellens, R.; Grandcolas, P. Phylogeny of Dictyoptera: Dating the Origin of Cockroaches, Praying Mantises and Termites with Molecular Data and Controlled Fossil Evidence. PlosOne, 2015, 10, e 0130127. doi: https://doi.org/10.1371/journal.pone.0130127

6. Stay, B.; Roth, L.M. The Colleterial Glands of Cockroaches. Ann. Entomol. Soc. Am. 1962, 55, 124-130. doi: https://doi.org/10.1093/aesa/55.1.124

7. Courrent, A.; Quennedey, A.; Nalepa, C.A.; Robert, A.; Lenz, M.; Bordereau, C. The fine structure of colleterial glands in two cockroaches and three termites, including a detailed study of Cryptocercus punctulatus (Blattaria, Cryptocercidae) and Mastotermes darwiniensis (Isoptera, Mastotermitidae). Arthropod Struct. Dev., 2008, 37, 55-66. doi: https://doi.org/10.1016/j.asd.2007.03.004

8. Pryor, M.G.M. Sclerotization. In Comparative biochemistry. Florkin, M.; Mason, H.S. Eds. Academic Press, 1962, pp. $371-396$.

9. Weesner, F.M. The reproductive system. In The Biology of Termites. Krishna, K.; Weesner, F.M. Eds. Academic Press: New York; pp. 125-160.

10. Grassé, P.P. Termitologia I. Anatomie, physiologie, reproduction des termites. Masson: Paris, 1982; 676p. 
11. Soltani-Mazouni, N.; Bordereau, C. Changes in the cuticle, ovaries and colleterial glands during the pseudergate and neotenic molt in Kalotermes flavicollis (FABR.) (Isoptera: Kalotermitidae). Int. J. Insect Morph. Emb., 1987, 16, 221-235. doi: https://doi.org/10.1016/0020-7322(87)90022-5

12. Rust, M.K.; Su, N.Y. Managing Social Insects of Urban Importance. Annu. Rev. Entomol., 2012, 57, 355-375. doi: https://doi.org/10.1146/annurev-ento-120710-100634

13. Grace, J.K. Invasive termites revisited: Coptotermes gestroi meets Coptotermes formosanus. In Proceedings of the 10th Pacific-Rim Termite Research Group Conference. Kuala Lumpur, Malaysia, 2014. Foschler, B.T. Ed. PL:1.

14. Costa-Leonardo, A.M. Cupins praga: Morfologia, biologia e controle. Divisa: Rio Claro, 2002; 128p.

15. RStudio Team. 2020. RStudio: Integrated Development for R. RStudio, PBC, Boston, MA. http://www.rstudio.com/.

16. Amornsak, W.; Noda, T.; Yamashita, O. Accumulation of glue proteins in the developing colleterial glands of the silkworm, Bombyx mori. J. Ser. Sci. Jap. 1992, 61, 123-130. doi: https://doi.org/10.11416/kontyushigen1930.61.123

17. Sturm, R.; Polhammer, K. Morphology and development of the female accessory sex glands in the cricket Teleogryllus commodus (Saltatoria: Ensifera: Gryllidae). Inv. Rep. Dev. 2000, 38, 13-21. doi: https://doi.org/10.1080/07924259.2000.9652432

18. Sturm, R. Morphology and ultrastructure of the accessory glands in the female genital tract of the house cricket, Acheta domesticus. J. Insect. Sci. 2012, 12, 99. doi: https://doi.org/10.1673/031.012.9901

19. Chapman, R.F.; Simpson, S.J.; Douglas, A.E. The insects: Structure and function. $5^{\text {th }}$ ed. Cambridge University Press: Cambridge., 2013; 929p.

20. Marchini, D.; Bernini, L.F.; Marri, L.; Giordano, P.C.; Dallai, R. The female reproductive accessory glands of the medfly Ceratitis capitata: Antibacterial activity of the secretion fluid. Insect Biochem., 1991, 21, 597-605. doi: https://doi.org/10.1016/00201790(91)90029-E

21. Belardinelli, M.; Fausto, A.M.; Guerra, L.; Buonocore, G.; Maroli, M.; Mazzini, M. Lipase and antibacterial activities of a recombinant protein from the accessory glands of female Phlebotomus papatasi (Diptera: Psychodidae). Ann. Trop. Med. Parasit. 2005, 99, 673-682. doi: 10.1179/136485905X51472

22. Yang, L.; Gao, Q.; Dai, J.; Yuan, G.; Wang, L.; Qian, C.; Zhu, B.; Liu, C.; Wei, G. Comparative transcriptome analysis of silkworm, Bombyx mori colleterial gland suggests their functional role in mucous secretion. PloSOne, 2018, 13, e0198077.

23. Ma, N.; Wang, M.; Hua, B. Ultrastructure of female accessory glands in the scorpionfly Panorpa sexspinosa Cheng (Mecoptera: Panorpidae). Tiss. Cel., 2013, 45, 107-114. doi: https://doi.org/10.1016/j.tice.2012.09.010 